\title{
O contexto procedimental das ações diretas no controle de constitucionalidade e a conversibilidade das "jurisdições"
}

\author{
Glênio José Wasserstein Hekman*
}

\section{INTRODUÇÃO}

O objetivo deste trabalho é trazer à discussão a necessidade de reavaliar conceitos que são importados do direito processual clássico para o processo constitucional que, se de um lado homogenizam este, ordinarizando-o, de outro, revelam-se incapazes de fazer frente às novas exigências da sociedade brasileira, em constante mutação. Carecendo de disciplina própria, organizada em estatuto processual que consolide princípios e normas, o processo constitucional transforma-se em algo místico, inacessível, reduzido e miscigenado que é às velhas fórmulas privatistas de processo, a confundir, ainda mais, sua função e finalidade. Daí que, a experiência jurídica costuma "costurar" tais conceitos, com ares de definitividade quando, em verdade, eles podem e devem sofrer a crítica para se saber até que ponto são flexíveis e adaptáveis à nova realidade (como conceitos abertos), ou se a dogmática processual contemporânea não foi concebida para prospectar além de sua postura conservadora, apresentando dificuldades de espaço para a discussão dessa relevante temática. É o que veremos!

\section{ORDINARIZAÇÃO DO PROCESSO}

Não há dúvidas que o processo constitucional deva merecer um tratamento disciplinatório-normativo especial para, dessarte, afastar-se do

\footnotetext{
* Professor de Direito da Univeridade Luterana do Brasil/ULBRA e da Universidade Federal do Rio Grande do Sul/UFRGS, Advogado, Mestre em Direito do Estado pela UFRGS e Doutor em Direito do Estado pela Universidade de São Paulo/USP.
} 
domínio dogmático do processo civil comum. De fato, a tentativa de explicar o processo constitucional a partir da influência clássica e remansosa que sofre daquele, deixa a desejar, já que pressiona o jurista a operar com institutos que se revelam inadequados pela diversidade de vertentes, a conciliar conceitos e procurar o equilíbrio de princípios eventualmente interexcludentes, tendentes a produzir eficácia incompleta ou duvidosa, ainda mais quando se lhe transporta uma visão privatista e individualista desses institutos, sem atentar que, de há muito, fruto da multiplicidade e complexidade das relações inter-humanas, os interesses individuais passam a ser coletivos, na medida em que a lesão ou ameaça de lesão a direito de um indivíduo indica a lesão ou ameaça de lesão a direito de toda a coletividade. ${ }^{1}$ Adroaldo Furtado Fabrício analisa o fenômeno experimentado pelo Direito, principalmente nas últimas décadas, $\mathrm{e}$ afirma não ser um despropósito que cada vez mais se fale acerca da publicização do Direito Privado, "no sentido de que a carga de interesse público envolvido nas relações do Direito dito "Privado" tende a crescer constantemente,"'2 a exigir, em correspondência, "uma impostação mais publicística do processo, inclusive do processo "civil", que na verdade é, para o nosso sistema, todo processo nãopenal." ${ }^{3}$ Por uma questão racional, os interesses coletivos devem ter primazia sobre o individual (disponível), já que o homem vive em sociedade, embora, é certo, deva existir um núcleo intangível na esfera da personalidade individual, para que o próprio homem possa se desenvolver na sociedade. Não é possível crer, no entanto, a não ser num sistema de méritos e deméritos, que somente um ou alguns indivíduos possam usufruir dos efeitos da norma jurídica, através do processo, ao passo que o restante coletivo fica relegado a um segundo plano, de acordo com a conveniência da política vigente ("como

1 Nesse sentido, Vitalino Canas observa que: "o direito processual constitucional não pode deixar de ser um direito processual autônomo, regido por princípios próprios, necessariamente pouco fungíveis com os dos processos jurisdicionais típicos. Estes últimos têm por fim resolver lides ou conflitos intersubjetivos de interesses que se manifestem em concreto. E se não se quiser ficar preso no conceito, porventura demasiado rígido, de lide, pelo menos terá de se reconhecer que nesses processos vêm sempre envolvidos interesses subjectivos" (CANAS, Vitalino. Os processos de fiscalização da constitucionalidade e da legalidade pelo Tribunal Constitucional: natureza e principios estruturantes. Coimbra: Coimbra, 1986, p. 87).

2 FABRÍCIO, Adroaldo Furtado. As novas necessidades do processo civil e os poderes do juiz. Estudos Jurídicos, v. 25, n. 64, p. 57-63, maio/ago. 1992. p. 61.

3 Ibidem, p. 62. 
se o processo não fosse instrumento eminentemente social. ${ }^{\prime 4} \mathrm{Se}$ a isonomia legal significa tratar desigualmente os desiguais na justa medida desta desigualdade, há um princípio que deve ser observado para que esta afirmação tenha sentido e possa ser efetivada: o da igualdade de oportunidades. Assim, de um berço comum, os indivíduos passam a se desenvolver, segundo as suas capacidades intrínsecas, e o sistema de méritos e deméritos, nessa convenção, torna-se justo, ou pelo menos, racionalmente aceitável. Mas isso, evidentemente, não é o que ocorre, até porque, a história nos ilustra, a concentração do poder, por qualquer que seja a forma pela qual ele se revele, pressupõe a desigualdade social. Esta desigualdade precisa ser amenizada, e não é sem razão que os Estados modernos tenham sua preocupação voltada para esse aspecto, como o Brasil que, em sua Carta Constitucional de 1988, o tem como objetivo fundamental (art. $3^{\circ} \mathrm{daCF} / 88$ ). Cumpre ao Estado, portanto, criar instrumentos de acesso à justiça para aqueles que, vítimas da desigualdade social, são excluídos da eficácia normativa individual, consequiência de um processo "privado-elitista", mas que encerra, em seu bojo, questão de interesse geral. Assim, não só para a efetivação dos direitos previstos na Constituição, mas na defesa de seus princípios, ação, processo e jurisdição são conceitos que devem ser permanentemente discutidos e atualizados, sob pena de aprisionar os operadores do direito, tornando-os incapazes de enfrentar os desafios que as novas relações impõem ao mundo jurídico.

De acordo com Rodolfo Mancuso, "os interesses metaindividuais (difusos, coletivos, individuais homogêneos) estão hoje alçados ao nível constitucional (CF, arts. 127 e 129, III)". Além disso, leis especiais compõem um sistema integrado, no sentido de possibilitar "uma tutela adequada e efetiva desses interesses, que de outra forma não teriam acesso à justiça em modo apropriado, já que o CPC, sendo um corpo de normas de origem romanística, está voltado para a solução de conflitos intersubjetivos, de tipo Tício versus Caio."

O Estado, portanto, procura equalizar as diferenças oferecendo meios de tutela coletiva, abrangendo aqueles que, por um motivo ou outro, estariam afastados do acesso à justiça.

No entanto, no que tange ao controle de constitucionalidade, é

\section{Ibidem.p. 63.}

5 MANCUSO, Rodolfo de Camargo. Manual do consumidor em juizo. 2.ed. São Paulo: Saraiva. 1998. p. 4.

6 Ibidem, p. 5. 
possível verificar que o mesmo ainda espelha desigualdade social, notadamente na modalidade do controle concreto de normas, quando a questão constitucional posta em exame rende apenas dividendos inter-partes, obrigando a coletividade a promover ações individuais para buscar os mesmos efeitos, nem sempre obtidos, dando margem à insegurança jurídica.

Assim, de fato, tais inconvenientes são superados pela modalidade de controle em tese.

\section{PODER JUDICIÁRIO E A NATUREZA DE SUA ATUAÇÃO}

Cabe aqui registrar, no entanto, que o contexto procedimental das ações diretas no controle de constitucionalidade, a partir de sua origem, tem como cenário de fundo a idéia de que o controle, na jurisdição constitucional, se desenvolve precipuamente para assegurar a coerência do sistema normativo e somente secundariamente, ou por conseqüência, para proteger eventuais lesões ocasionadas pela lei ou ato normativo às posições subjetivas constitucionalmente garantidas. Qual é, no entanto, a natureza da atuação do Poder Judiciário neste contexto?

$\mathrm{Na}$ obra Jurisdição e competência, Athos Gusmão Carneiro afirma que a "Constituição Federal atribui ao Poder Judiciário, mais especificamente ao Supremo Tribunal Federal, o exercício, embora sob vestes jurisdicionais, de uma atividade legislativa, porque não vinculada à aplicação do direito a um caso concreto." Refere ele às hipóteses então previstas de ação direta;

7 CARNEIRO, Athos Gusmão. Jurisdição e competência. 2. ed., São Paulo: Saraiva, 1983, p. 16. Na doutrina italiana, conforme se pode perceber da leitura de Mauro Cappelletti (Pronunce di rigetto nel processo costituzionale delle libertà e cosa giudicata. Rivista di Diritto Processuale, Padova, v. 11, n. 1, p. 135-166, 1956.), há a posição adotada por Calamandrei que reconhece a natureza legislativa da função exercida pela Corte constitucional, notadamente ante a eficácia erga omnes da pronúncia. Por outro lado, afirma que a doutrina dominante italiana, assim como aquela dos países de língua alemã, defende a jurisdicionalidade da função atribuída à Corte, podendo-se notar, em CARNELUTTI E ALLORIO apud CAPPELLETTI, op. cit. p. 138), ser característica essencial e imprescindível dos provimentos "jurisdicionais", aquela de criar a coisa julgada substancial. No entanto, Cappelletti não concorda com a posição dominante. Segundo ele, o que distingue a jurisdição das outras "funções" é um elemento puramente formal, modal, isto é como se posicionam os sujeitos da relação processual considerada, e não pelo resultado da atividade exercitada, razão pela qual prefere o critério da "terzietà", característica particularmente evidenciada no juízo constitucional, quando exercita o poder de decidir sobre a questão que lhe é submetida (CAPPELLETTI, op. cit. p. 140-141). Até porque, não reconhece a formação de coisa julgada na sentença de rejeição da inconstitucionalidade, pelo fato de a questão poder voltar a ser decidida, mais tarde, por fundamento diverso. 
uma para declarar a inconstitucionalidade (visando excluir a eficácia da lei ou ato normativo impugnado), outra, para firmar interpretação, em tese, de lei ou ato normativo federal ou estadual, sem provocar a sua nulidade ou cassação (equivalendo ou funcionando de modo materialmente idêntico, a decisão do Supremo, a uma lei declaratória ou interpretativa). Esse controle genérico antecipase ao conflito concreto de interesses por meio de ações preventivas e saneadoras.

Galeno Lacerda, na mesma linha, ao comentar as inovações então introduzidas pela Emenda Constitucional $\mathrm{n}^{\circ} 7$, de 13.4 .77 , no que tange à interpretação, em tese, foi categórico em dizer que, o Supremo Tribunal Federal passa a atuar de forma legiferante, ao se confundir jurisdição e legislação, em razão da coisa julgada que torna a exegese vinculativa, posto que a "hermenêutica se consolida em obrigatória e imutável." se introduzam novas disposições à lei existente.

A confusão de funções, nessa perspectiva, não aparece de forma clara na obra de Edson Prata, que ressalta apenas dúvidas quanto a separar funções administrativas das judiciárias, notadamente no campo da jurisdição voluntária. Assim, para o citado autor:

Pela função legislativa, o Estado elabora as normas gerais e abstratas com o objetivo de regular a atividade das pessoas e dos órgãos públicos. É essencialmente criadora, e criadora do próprio direito.

A função jurisdicional, ao revés, objetiva atuar a norma legal nos casos concretos que lhe são submetidos, distribuindo justiça aos requerentes. Declara a lei, o direito ao caso concreto. A lei criada pelo Poder Legislativo é seu principal material de trabalho. Obriga-se a declará-la, salvo quando se reveste de inconstitucionalidade, caso em que também a própria inconstitucionalidade é declarada, deixando a lei, conseqüentemente, de ser cumprida. ${ }^{9}$

De qualquer sorte, é possível imaginar, na atuação jurisdicional, atos judicialiformes que, se não visam diretamente a aplicação do direito ao caso concreto, o fazem indiretamente, criando-lhe acessos ou afastando entraves para este objetivo.

\section{O PROCESSO OBJETIVO E JURISDIÇÃO}

É corrente, na doutrina e jurisprudência nacionais mais recentes,

8 LACERDA, Galeno. Comentários ao código de processo civil: lei n. ${ }^{\circ}$ 5.869, de 11.01.73. Rio de Janeiro: Forense, 1981. v.8, t.1.p. 77-78.

9 PRATA, Edson. Jurisdição voluntária, São Paulo: Leud, 1979, p. 111. 
que as ações diretas inauguram autêntico processo objetivo. ${ }^{10} \mathrm{~A}$ dúvida que resta, portanto, é saber se essas ações instituem processos clássicos de jurisdição contenciosa ou se, na realidade, instituem "procedimentos judicialiformes", que partem da jurisdição voluntária ${ }^{11} \mathrm{e}$, posteriormente, se convertem, pela transmutação da espécie, posto que a jurisdição é una (poder indivisível), em face dos efeitos que visa a atingir.

Em que pese as numerosas críticas contra a expressão "jurisdição voluntária", indicando que esta, de acordo com
Zamora, Lopes da Costa e Mortara, não seria nem voluntária nem jurisdição (apenas administração pública de interesses privados), ${ }^{12}$ certo é que sem o domínio de certeza em torno da temática, volta e meia ressurge e com força, a sustentação da jurisdicionalidade dos atos nela inseridos, havendo ainda quem a enxergue como uma atividade mista, eis que substancialmente administrativa e formalmente jurisdicional. ${ }^{13}$

Como bem refere Maria Luiza Ahrends Maraninchi, "a atuação jurisdicional não pode ficar adstrita aos casos em que se dá o litígio", ${ }^{14}$ pois “há

10 Ver, nesse sentido, FERREIRA MENDES, Gilmar. Jurisdição constitucional: o controle abstrato de normas no Brasil e na Alemanha. 3. ed. São Paulo: Saraiva, 1999. p. 131-132 e nota de rodapé $\mathrm{n}^{\circ} 37$.

11 De acordo com Athos Gusmão Carneiro: "os atos praticados no exercício da jurisdição voluntária são atos judiciais, porque praticados por juízes; mas não são atos jurisdicionais, pois ao praticá-los o juiz não está aplicando o direito com vista a eliminar um conflito de interesses, mas sim com o propósito de influir em um negócio privado ou em uma situação jurídica. O juiz, no exercício da jurisdição voluntária, pratica atos subjetivamente judiciais, mas substancialmente administrativos" (CARNEIRO. Jurisdição e... p. 34). Embora a afirmação tenha um peso bastante significativo para a doutrina dominante, ainda assim é restrita, hajam vista os argumentos de Salvatore Satta, Rafael de Pina, Amilcar de Castro e Marcos Afonso Borges, partidários de uma conceituação mais ampla da jurisdição (citados por CARNEIRO, op. cit. p. 33), e defendendo ser a jurisdição voluntária verdadeira jurisdição por tratar-se de poder-dever que o judiciário deverá exercer toda vez que se manifestar acerca do que the é levado a apreciar, resolvendo a situação exposta, quer seja ela litigiosa ou não. Daí não ser necessária a existência de um conflito de interesses para que a lei seja aplicada com o objetivo de eliminar o litígio, bastando a necessária presença do judiciário para resolver aquilo que as partes ou interessados não podem resolver por si mesmos. Em outras palavras, a presença de um "terzietá", ou terceiro imparcial, é necessária para fazer a mediação entre a norma abstrata e seus efeitos concretos.

12 Ver: PRATA. Jurisdição... p. 16.

13 Ver: PORTO, Sérgio Gilberto. Jurisdição voluntária: atividade administrativa ou jurisdicional? Revista Jurídica, São Paulo, v. 31, n. 104, p. 90-95, mar./abr. 1984. p. 92-93.

14 Ver: MARANINCHI, Maria Luiza Ahrends. Natureza jurídica da jurisdição voluntária. Estudos Jurídicos, São Leopoldo, v. 19, n. 45, p. 45-67, jan./ abr. 1986. p. 51. 
determinadas categorias de interesses não conflitantes, especiais, as quais não podem prescindir da intervenção judicial". ${ }^{15}$ Assim, parece-me ser insuficiente toda e qualquer conceituação de jurisdição, que restringe este poder estatal à composição de conflitos, mediante aplicação da lei ao caso concreto. Com certeza, esta é sua faceta mais visível, mas não se pode descuidar que, na administração da justiça e do bem-comum, as funções do Estado também se relacionam e se combinam. Daí que, mais ponderado, Enrico Allorio preferiu uma saída mais estratégica, ao afirmar que se deve definir o instituto com base em seus efeitos, portanto, se resulta coisa julgada é jurisdição, se não resulta não é. $\mathrm{Na}$ verdade, refere que o emprego da forma do processo declarativo, mais a coisa julgada como seu resultado, definem a jurisdicionalidade do processo. ${ }^{16}$ Embora também passível de crítica, ${ }^{17}$ a tese tem inegavelmente uma virtude, e nesse ponto incontestável, que pelo menos o efeito declaratório substancialmente considerado na decisão (apto a produzir coisa julgada), e se juris dictio é dizer o direito, é sinal inequívoco de existência de jurisdição. A moderna doutrina, no entanto, acolhe a tese de que a jurisdição voluntária se constitui em atividade tipicamente jurisdicional, especialmente pela presença de um "terzietà", ou seja, do juiz estranho e imparcial a decidir sobre a causa que lhe é proposta. ${ }^{18} \mathrm{~A}$ presença subjetiva de integrante do Poder Judiciário e da atividade que lhe é rotineira, qual seja a da verificação de legalidade dos atos, conduz, com maior facilidade, à aceitação de um critério de forma de controle constitucional, constituído pela natureza do órgão de controle.

Nesse sentido, as ações diretas no controle de constitucionalidade aproximam-se, coincidentemente, na busca do efeito antes referido, ou seja, visam a declarar a existência ou não de vício da norma ou ato normativo atacado em tese, a fim de lhes atribuir conseqüências moduláveis no tempo e no espaço. $E$ isso ocorrerá sempre, no intuito de manter a higidez da

15 Ibidem.

16 ALLORIO, Enrico. Saggio polemico sulla giurisdizione volontaria. Rivista Trimestrale di Diritto e Procedura Civile, Milano, v. 2, p. 487-529, 1948. p. 510-516. Segundo Ovídio A. Baptista da Silva: "a doutrina que identifica jurisdição com coisa julgada tem mais adeptos no Brasil do que se imagina", identificando-a em Frederico Marques, Arruda Alvin, A. A . Lopes da Costa, Grinover-Dinamarco-Cintra e Kasuo Watanabe (SILVA, Ovídio Baptista da. Curso de processo civil. Porto Alegre: Fabris, 1987. v.1. p. 23).

17 Com relação às objeções levantadas à posição de Allorio, ver SILVA. Curso....p. 23).

18 Ver: PORTO Jurisdição... p. 95. 
Constituição e dos princípios e garantias nela estabelecidos. Porém, neste contexto, ao contrário da linha seguida pelos processualistas clássicos, não é possível se dar o mesmo tratamento das ações processuais comuns, ou de jurisdição contenciosa que a elas se relaciona, ao menos inicialmente, às ações diretas do controle de constitucionalidade, por não serem elas portadoras do conjunto de características que identificam sua exata pertinência a esse campo específico da jurisdição. Se não, vejamos! Costuma-se, em doutrina, cotejar os elementos diferenciadores entre a atividade jurisdicional e a atividade administrativa. Tem-se, portanto e simplificadamente, relembrando o quadro comparativo elaborado por Sérgio Gilberto Porto, que: 1) a atividade jurisdicional: depende da iniciativa da parte; o juiz faz atuar a lei; pressupõe uma lide, pois existem partes com interesses conflitantes; é uma atividade substitutiva; há um processo; resulta coisa julgada material; presença de um terceiro imparcial (terzietà); satisfaz interesse de outro; e 2) a atividade administrativa: normalmente não depende de qualquer requerimento; o administrador age conforme a lei; não pressupõe uma lide, pois existem apenas interessados; é uma atividade originária, há simplesmente um procedimento; não resulta coisa julgada; não há terceiro imparcial, satisfaz interesse próprio.
Desse cotejo, prossegue Sérgio Gilberto Porto, ressaltariam as seguintes divergências:

a) haveria diversidade de escopo entre a jurisdição contenciosa $e$ a voluntária, pois enquanto a primeira tem caráter repressivo, a segunda tem caráter preventivo; b) enquanto a iurisdição contenciosa é uma atividade declarativa de direitos, a voluntária se destina à formação de atos e negócios jurídicos, tendo, portanto, função constitutiva, estranha à natureza da jurisdição; c) na iurisdição voluntária não há litígio, nem contraditório, portanto não existem partes, mas apenas interessados, ao passo que na contenciosa existem partes, litigio e contraditório; d) os atos de jurisdição voluntária não produzem coisa iulgada material, ao passo que os atos de jurisdição contenciosa produzem coisa julgada material; e) finalmente que a jurisdição voluntária seria simples administração pública de interesses privados. ${ }^{19}$

As ações diretas não contemplam a existência de partes, pelo menos no sentido do processo comum. Há um requerente, mas não necessariamente um requerido. Sempre se teve a idéia, no Brasil, de que o Procurador-Geral da República e, atualmente, todos os legitimados constitucionalmente para propor ações diretas, são substitutos processuais, no exercício de uma atividade do interesse público, ou seja,

19 PORTO Jurisdição... p. 94. 
atuam como representantes da sociedade. ${ }^{20} \mathrm{E}$, completando a relação processual, num simulacro de partes, ou de interesses opostos, antes da Constituição Federal de 1988, apresentava-se a mesma figura do Procurador-Geral da República, substituído que foi pelo Advogado-Geral da União, atualmente, com o mister de representar os interesses da União, em juízo. Faz acreditar, portanto, que as ações diretas são ações públicas movidas pela sociedade contra a União, o que não é verdade. A propósito da representação, conforme aduz Arthur de Castilho Neto, "construiu a Suprema Corte o entendimento que é ela uma ação sem réu, simplesmente porque não há estado jurídico a modificar, isto porque a lei ou ato constitucional não adquiriu eficácia". ${ }^{21}$ São elas ações públicas de que o próprio Estado se vale (como poder-dever decorrente da própria Constituição), através de seus órgãos ou entes delegados, para expurgar ou adequar no ordenamento jurídico, normas ou atos normativos de constitucionalidade duvidosa. Semelhança pode ser buscada no processo penal que, segundo informa Hélio Tornaghi, ${ }^{22}$ no que tange à ação penal pública, o titular da ação é o próprio Estado, onde o Ministério Público é apenas um órgão dele, seguindo, de regra, o princípio da oficialidade. ${ }^{23}$ Além disso, tanto as ações diretas, em virtude de sua natureza e finalidade, quanto a ação penal pública, não são suscetíveis de desistência. ${ }^{24}$

Interessante salientar que a legislação brasileira já considerou, como modalidade de ação pública, a ação de ofício, movida pelo juiz ou autoridade policial. No saber de Tornaghi, nesses casos "não há propriamente ação, mas

20 Nesse sentido, conferir em FERREIRA MENDES. Jurisdição...p. 61. Por outro lado, outra versão pode ser encontrada. Assim: "a titularidade dessa ação especialíssima foi deferida pelas sucessivas disposições constitucionais unicamente ao Chefe do Ministério Público Federal, tendo por finalidades específicas manter o equilíbrio entre os Poderes Políticos do Estado e preservar sua instituição" (Repr. 1.161 - Questão de Ordem - rel. Min. Néri da Silveira, RTJ 113/22).

21 CASTILHO NETO, Arthur de. Reflexões críticas sobre a ação direta de constitucionalidade no Supremo Tribunal Federal. Revista da Procuradoria-Geral da República, São Paulo, n.. 2, p. 11-39, jan./mar. de 1993.p. 13.

22 TORNAGHI, Hélio Bastos. Instituições de processo penal. São Paulo: Saraiva, 1977. v.2. p. 317 et seq.

23 Nas demais ações penais, a própria lei penal concede legitimidade concorrente ou privativa ao ofendido (mas, por evidente, o interesse privado, aqui, deve-se revelar por proteção dos direitos privativos da personalidade do ofendido).

24 Ver arts. $5^{\circ}$ e 16 da Lei n ${ }^{\circ} 9.868$, de 10 de novembro de 1999. 
procedimento judicial independente de ação. Mas a lei fala em ação. É o que se infere do disposto nos arts. $17 \mathrm{da}$ Lei das Contravenções Penais e 26 do Código de Processo Penal." 25 Muito embora, por certo, o Código brasileiro seguisse o princípio ne procedat iudex ex officio, é possível demonstrar pelo exposto, que o uso dos conceitos de processo sofre, no tempo e no espaço, mutações que não permitiram a criação de uma teoria pura infensa a críticas, terminando por polemizar a matéria jurisdicional na sua exata compreensão, sem que se pudesse encontrar critério definitivo que a afastasse da atividade administrativa. ${ }^{26}$

Por outro lado, conforme já foi dito acima, as ações diretas têm função preventiva (eis que previnem futuras lides), não há litígio ou interesses subjetivos contrapostos ou contraditório, como antes se afirmava com veemência, principalmente com relação à ação declaratória de constitucio- nalidade, e agora menos (no que tange à inexistência de contraditório), pela introdução de providências de caráter pluralista, pela nova lei que regulamenta o processo e julgamento da ação direta de inconstitucionalidade e da ação declaratória de constitucionalidade, permitindo que outros titulares do direito de propositura da ação direta possam manifestar-se e requerer, positivando a figura do amicus curiae, e ensejando ao Tribunal o conhecimento pleno dos diversos aspectos envolvidos na questão, com a investigação integrada de elementos fáticos e jurídicos. ${ }^{27}$

\section{CONCLUSÃO}

De fato, elementos da jurisdição voluntária estão presentes no início da ação direta. Ocorre que, para os efeitos da coisa julgada da declaração de inconstitucionalidade/constitucionalidade, impossível de ser obtida pela via da jurisdição voluntária, ${ }^{28}$ faz-se

25 TORNAGHI, op. cit. p. 318.

26 Observe-se a afirmação de José Maria Rosa Tesheiner, com relação ao processo penal inquisitório: "...já não existe no Brasil (Constituição Federal, art. 129, I). Se existisse, caberia falar de uma 'função de administração da justiça', sem caráter jurisdicional" (TESHEINER, José Maria. Jurisdição voluntária. Rio de Janeiro: Aide, 1992. p. 25).

27 Ver: FERREIRA MENDES, Gilmar. Processo e julgamento da ação direta de inconstitucionalidade e da ação declaratória de constitucionalidade perante o Supremo Tribunal Federal: uma proposta de Projeto de Lei. Cadernos de Direito Tributário e Finanças Públicas, São Paulo, v. 6, n.. 23, p. 10-23, abr./jun. de 1998. p. 10-11.

28 Para Galeno Lacerda, "a diferença fundamental entre jurisdição e administração reside na eficácia do ato. $\mathrm{O}$ ato jurisdicional, ao aplicar a lei, impõe um vínculo por si só eficaz às partes e ao próprio juiz. A eficácia lhe é imanente, porque pertence à sua própria natureza. O ato administrativo não possui essa eficácia absoluta, pois sempre poderá ser submetido à jurisdição. Por isto, dele jamais nascerá a preclusão ou a coisa julgada" (LACERDA, Galeno. Despacho Saneador. Porto Alegre: La Salle, 1953.p. 104). 
necessária sua conversão em contenciosa. De outra parte, conforme nos revela Galeno Lacerda:

Onde houver, portanto, julgamento de questão, ai estaremos em presença de ato jurisdicional. Isto significa que a iurisdição também, pode se introduzir em procedimento de natureza administrativa, como os da impropriamente chamada "jurisdição" voluntária, sempre que, neles, se suscitar qualquer questão que requeira juizo, isto é, iulgamento para dirimir controvérsia. Neste caso, o procedimento se transforma de inter volentes em inter nolentes, fato que faz nascer automaticamente a jurisdição, porque tornada presente a causa, que é a lide, o conflito, embora sobre aspecto secundário como o meramente processual. ${ }^{29}$

Aceitando-se a ocorrência da conversibilidade, em qual momento será possível a sua verificação? Creio que o momento é o da decisão sobre a questão constitucional. À decisão serão emprestados os efeitos necessários da coisa julgada erga omnes e vinculante, temperando-se os demais efeitos (ex tunc, ex nunc ou pro futuro) de acordo com o alcance às situações concretas da vida, mitigando-se excessiva rigidez.

Os elementos de jurisdição voluntária e contenciosa, somados a uma atividade "legislativa" pelo Poder Judiciário, numa combinação de substância e forma, ${ }^{30}$ induzem à crença de tratar-se o ato procedimental que origina o controle pela via de ação direta, como decorrente do próprio poder soberano do Estado, onde, na doutrina Kelseniana, ele se confunde com a ordem jurídica. ${ }^{31}$ A manutenção e funcionalidade, ou melhor, da garantia da ordem necessita da unidade das funções do Estado, embora o exercício

29 LACERDA. Comentários... p. 23. Maria Berenice Dias vê, na posição sustentada, onde se procura identificação da atividade jurisdicional apreciadora da lide, "um apego, ainda que não revelado, à teoria civilista da ação, restando por restringir o campo de atividade do Poder Judiciário" (DIAS, Maria Berenice. Juridição voluntária e coisa julgada. Estudos Jurídicos, São Leopoldo, v. 21, n. 49, p. 53-72, maio/ago, de 1987. p. 59). A referida desembargadora do Tribunal de Justiça do Estado do Rio Grande do Sul defende o reconhecimento da jurisdição do procedimento voluntário e, de outra banda, conclui pela ocorrência de coisa julgada neste tipo de procedimento.

30 Sobre as possíveis combinações heterogêneas entre elementos próprios das diversas funções soberanas do Estado, ver: GODACCI-PISANELLI, G. Analisi delle funzioni sovrane. Milano: Giuffrè, 1946. p. 79-92.

31 Sobre o assunto, ver: GALEOTTI, Sergio. Introduzione alla teoria dei controlli costituzionali. Milano:. Giuffrè, 1963. p. 93-101, onde faz específica referência sobre a relação do controle e as funções soberanas, demonstrando não ser ele uma "quarta função estatal", mas presente em cada uma delas na sua relação horizontal e aos específicos atos de suas respectivas competências. 
da fiscalização ou competência, na prática, possa ser confiada, consti-

\section{REFERÊNCIAS}

ALLORIO, Enrico. Saggio polemico sulla giurisdizione volontaria. Rivista trimestrale di Diritto e Procedura Civile, Milano, v. 2, p. 487-529, 1948.

CANAS, Vitalino. Os processos de fiscalização da constitucionalidade e da legalidade pelo Tribunal Constitucional: natureza e princípios estruturantes. Coimbra: Coimbra 1986.

CAPPELLETTI, Mauro. Pronunce di rigetto nel processo costituzionale delle libertà e cosa giudicata. Rivista di Diritto Processuale, Padova, v. 11, n.1, p.135-166, 1956.

CARNEIRO, Athos Gusmão. Jurisdição e competência. 2. ed. São Paulo: Saraiva, 1983.

CASTILHO NETO, Arthur de. Reflexões críticas sobre a ação direta de constitucionalidade no Supremo Tribunal Federal. Revista da Procuradoria-Geral da República, SãoPaulo,n.2,p. 11-39, jan./mar. 1993.

DIAS, Maria Berenice. Juridição voluntária e coisa julgada. Revista Estudos Jurídicos, São Leopoldo, v. 21, n. 49, p. 53-72, maio/ago. 1987.

FABRÍCIO, Adroaldo Furtado. As novas necessidades do processo civil e os poderes do juiz. Estudos tucionalmente, a um de seus poderes; no caso brasileiro, ao Poder Judiciário.

Jurídicos, São Leopoldo, v. 25, n. 64, p. 57-63, maio/ago. 1992.

FERREIRA MENDES, Gilmar. Jurisdição constitucional: o controle abstrato de normas no Brasil e na Alemanha. 3. ed. São Paulo: Saraiva, 1999.

. Processo e julgamento da ação direta de inconstitucionalidade e da ação declaratória de constitucionalidade perante o Supremo Tribunal Federal: uma proposta de Projeto de Lei. Cadernos de Direito Tributário e Finanças Públicas, São Paulo, v. 6, n. 23, p. 10-23, abr.jun. de 1998.

GALEOTTI, Sérgio. Introduzione alla teoria dei controlli costituzionali. Milano: Giuffrè, 1963.

GODACCI-PISANELLI, G. Analisi delle funzioni sovrane. Milano: Giuffrè, 1946.

LACERDA, Galeno. Comentários ao código de processo civil; lei $\mathrm{n}{ }^{\circ}$ 5.869 , de 11.01.73. Rio de Janeiro: Forense, 1981. v.8, t.1.

- Despacho saneador. Porto Alegre: La Salle, 1953.

MANCUSO, Rodolfo de Camargo. Manual do consumidor em juizo. 2.ed. São Paulo: Saraiva. 1998.

MARANINCHI, Maria Luiza Ahrends. Natureza jurídica da jurisdição voluntária. Estudos 
Jurídicos, São Leopoldo, v. 19, n.. SILVA, Ovídio A. Baptista da. Curso 45, p. 45-67, jan./ abr. 1986. de processo civil. Porto Alegre:

PORTO, Sérgio Gilberto. Jurisdição voluntária: atividade administrativa ou jurisdicional? Revista Juridica, São Paulo, v. 31, n. 104, p. 90-95, mar./abr. 1984. Fabris, 1987. v.1

TESHEINER, José Maria Rosa. Jurisdição voluntária. Rio de Janeiro: Aide, 1992.

TORNAGHI, Hélio Bastos. Instituições

PRATA, Edson. Jurisdição voluntária. São Paulo: Leud, 1979. de processo penal. São Paulo: Saraiva, 1977.v.2. 
